\title{
Negatively charged nanoparticles produced by splashing of water
}

\author{
H. Tammet ${ }^{1}$, U. Hõrrak ${ }^{1}$, and M. Kulmala ${ }^{2}$ \\ ${ }^{1}$ Institute of Physics, University of Tartu, Ülikooli 18, 50090 Tartu, Estonia \\ ${ }^{2}$ Department of Physical Sciences, University of Helsinki, P.O. Box 64, 00014, Helsinki, Finland
}

Received: 7 July 2008 - Published in Atmos. Chem. Phys. Discuss.: 1 September 2008

Revised: 10 December 2008 - Accepted: 11 December 2008 - Published: 16 January 2009

\begin{abstract}
The production of splashing-generated balloelectric intermediate ions was studied by means of mobility spectrometry in the atmosphere during the rain and in a laboratory experiment simulating the heavy rain. The partial neutralization of intermediate ions with cluster ions generated by beta rays suppressed the space charge of intermediate ions but preserved the shape of the mobility distribution. The balloelectric ions produced from the waterworks water of high TDS (Total Dissolved Solids) had about the same mobilities as the ions produced from the rainwater of low TDS. This suggests that the balloelectric ions can be considered as singly charged water nanoparticles. By different measurements, the diameter mode of these particles was $2.2-2.7 \mathrm{~nm}$, which is close to the diameter of $2.5 \mathrm{~nm}$ of the Chaplin's 280-molecule magic icosahedron superclusters. The measurements can be explained by a hypothesis that the pressure of saturated vapor over the nanoparticle surface is suppressed by a number of magnitudes due to the internal structure of the particles near the size of $2.5 \mathrm{~nm}$. The records of the concentration bursts of balloelectric ions in the atmosphere are formally similar to the records of the nucleation bursts but they cannot be qualified as nucleation bursts because the particles are not growing but shrinking.
\end{abstract}

\section{Introduction}

\subsection{Historical overview}

The Earth's climate is largely controlled by the atmospheric aerosol, which modifies the radiative transfer directly as well as indirectly via clouds (Forster et al., 2007). The impact of aerosol particles essentially depends on their size distribu-

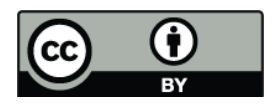

Correspondence to: $\mathrm{H}$. Tammet (hannes.tammet@ut.ee) tion. A large number of small particles act in different way when compared with a small number of large particles composed of the same amount of suspended mass. Therefore, understanding the generation and evolution mechanisms of atmospheric aerosol particles, starting in the nanometer size range, is a fundamental task of atmospheric physics and chemistry. Initial processes, which occur in the particle diameter range below $10 \mathrm{~nm}$ are the subjects of extensive research (Kulmala et al., 2004, 2007; Winkler et al., 2008) but still not enough is known about them today. The nanometer particles arise in the nucleation burst events and one of the methods of detecting these particles is the measuring of intermediate ions (Hirsikko et al., 2007). Hõrrak et al. (2000) identified the intermediate ions as the air ions of the mobility of $0.034-0.5 \mathrm{~cm}^{2} \mathrm{~V}^{-1} \mathrm{~s}^{-1}$ and the corresponding diameter of 1.6-7.4 nm. Most of the concentration bursts of intermediate ions are explained as atmospheric aerosol nucleation events, produced during abrupt intensifications of the gas-toparticle conversion. Exceptions are the bursts of intermediate ions, which happen during the rain (Hõrrak et al., 2006; Hirsikko et al., 2007). These bursts are usually associated with the balloelectric effect, which means the generation of the electric charge by the splashing of water. For the sake of brevity, the intermediate ions generated by the splashing of water are called the balloelectric ions below. The term "balloelectricity" was introduced by Christiansen (1913), based on the Latin word ballista, which denotes a stone throwing machine.

Balloelectric effect has been known for already a long time. Philipp Lenard began the first comprehensive scientific discussion of the balloelectric effect with the words "Es ist lange bekannt, dass Wasserfälle die Luft in ihrer Umgegend mit negativer Electricität beladen" (Lenard, 1892). Since the publication of this paper, the balloelectric effect has often been called the Lenard effect. In the first period of the research in the beginning of the last century, much information was gained about the creating of the space charge in

Published by Copernicus Publications on behalf of the European Geosciences Union. 
the air depending on the chemical composition of the liquid and the conditions of splashing. Several well known scientists e.g. Faraday, Lord Kelvin, J. J. Thomson, L. de Broglie, Townsend etc. participated in the early research (Christiansen, 1913). However, the properties of charge carriers and mechanism of charging remained poorly known. The new stage of research was opened by the second fundamental paper by Lenard (1915), where the former concept about the contact potential between the liquid and gas was rejected. The charging was explained as a result of the presence of complex molecules, such as $\mathrm{H}_{6} \mathrm{O}_{3}$ in the water and the disruption of the electric double-layer on the water surface. It was reasoned that the diameter of the carriers of the negative charge should be less than $15 \mathrm{~nm}$ compared with the thickness of the double-layer. The actual size distribution of charge carriers remained unknown. The latter can be explained by the absence of appropriate devices (ion spectrometers), especially for the measurements in the conditions of high relative humidity. The results of the early research were well reviewed by Gilbert and Shaw (1925) and by Bühl (1932). The review by Bühl did not refer to Gilbert and Shaw and the two independent reviews complement each other.

The electric double-layer mechanism of balloelectric effect generates negatively charged water droplets. Natanson (1951) studied an accompanying mechanism of creating the electric charges of droplets as a result of fluctuations of the ions in the bulk liquid during atomization. This mechanism generates equally both the negative and positive charges. The balance of the fluctuation mechanism and the unipolar balloelectric mechanism in the waterfall and raingenerated electricity has remained an open question till now.

Later, the balloelectric effect was used for creating the negative air ions in the physiotherapeutic apparatus, and the terms "hydroaeroions" and "electro-aerosols" were used to characterize these particles (Wehner, 1987). The natural balloelectric charging generates enough of charge for using in the physiotherapeutic apparatus (Salm and Tamm, 1963), but appears weak for technical applications. Burkhardt (1935) designed an atomizer, where the charge is induced on the surface of the liquid just in the atomizer. This method provides very high unipolar charges on the micrometer size range droplets. The induction charging of droplets during splashing in the external electric field is a substantially different physical mechanism when compared with the balloelectric effect. The physics of induction charging is simple (Tammet, 1963) and is not discussed in the present paper. However, the possible extra effect of induction charging must always be estimated in the experimental research of the balloelectric effect especially if the measurements are provided in the real atmosphere (Blanchard, 1958).

The detailed electric mobility distribution of the balloelectric charge carriers was first measured in the excellent laboratory experiments by Chapman $(1937,1938 a, b)$, who used a high resolution mobility spectrometer based on the prin- ciple by Erikson (1924). In addition to the ordinary cluster ions, the generation of the negative particles of the mobility of $0.2-0.4 \mathrm{~cm}^{2} \mathrm{~V}^{-1} \mathrm{~s}^{-1}$ was consistently shown. Although, the interpretation of the mobility distributions is limited and sometimes questionable, the experimental data by Chapman can be approved as exact and reliable.

Blanchard $(1955,1966)$ proposed an emission mechanism of the positive charge from oceans acting as a component of the global atmospheric electric circuit. The proposal is based on the fact that the balloelectric effect leaves the positive charge mostly on larger droplets after the disruption of bubbles generated by the waves. Later, Gathman and Hoppel (1970) showed that the Blanchard effect does not work over a fresh-water lake, where the bubbling generated the negative space charge. Reiter (1994) examined the wavegenerated space charge near the Mediterranean Sea and rejected Blanchard's hypothesis for the salt-water reservoirs as well. The particles of the size above $2.5 \mu \mathrm{m}$ appeared mostly positively charged, but the negative component of the space charge carried by smaller particles of a much higher number concentration proved to be dominating.

In spite of a large amount of laboratory research the mechanism of balloelectric effect during the rain, on the sea waves and near the waterfall is not well-known. An obvious reason is that the instruments, used in the laboratory research, were not suitable for measurements in the natural conditions. The first measurements of charge separation by the splashing of naturally falling raindrops, made by Levin (1971), were still limited to episodic measurements of the integral amount of the electric charge. First detailed data about the mobility distribution of the rain-generated charged nanometer particles were achieved only a few years ago (Hõrrak et al., 2006). A high-resolution instrument was first applied for measuring the mobility distributions of clusters and nanometer particles near the natural waterfall by Laakso et al. $(2006,2007)$.

\subsection{Unsolved problems}

The mechanism of creating water particles of the mobility of $0.2-0.4 \mathrm{~cm}^{2} \mathrm{~V}^{-1} \mathrm{~s}^{-1}$, which was experimentally proved by Chapman (1938a), is still not understood. These particles, if carrying one elementary charge, should have the diameters of $1.8-2.7 \mathrm{~nm}$ according to the size-mobility function by Tammet (1995), and contain 100-340 water molecules. A typical large raindrop has the equivalent mass diameter of about $2 \mathrm{~mm}$ and the falling speed of about $6.5 \mathrm{~m} \mathrm{~s}^{-1}$. If the kinetic energy of this raindrop is converted totally into the surface energy of smaller droplets of equal size, then we get the droplets of the diameter of about $20 \mu \mathrm{m}$. However, the kinetic energy of a $2 \mathrm{~mm}$ raindrop corresponds to the surface energy of $6.5 \times 10^{13}$ nanoparticles of the diameter of $2.5 \mathrm{~nm}$. These particles make up only about $0.01 \%$ of the mass of the initial raindrop. Thus the generating of a large number of nanoparticles still does not contradict the energy conservation. The mechanics of the fragmentation of 
droplets is extremely complicated (Fedorchenko and Wang, 2004; Villermaux, 2007). Despite of the advances in the high-speed imaging of droplet impact process (Thoroddsen, 2008), the details of the mechanisms of creating the nanoparticles have remained out of the range of today's quantitative research.

The larger microdroplets created in the process of fragmentation can attain the nanometer size as a result of evaporation. A rainwater microdroplet will leave dry residue, whose diameter is $1-2 \%$ of the initial size of the droplet. Thus the initial diameter of the microdroplets evaporating down to the diameter of $2.5 \mathrm{~nm}$ should not exceed $0.25 \mu \mathrm{m}$. It is not known whether the substance of $2.5 \mathrm{~nm}$ particles is the water or dry residue. Usually it is expected to be water; however, this assumption leads to a paradox of unexplained slow evaporation of balloelectric nanoparticles.

If the electric charge of a microdroplet exceeds the Rayleigh stability limit (see Fong et al., 2007)

$q_{R}=\pi \sqrt{8 \sigma \varepsilon_{0} d^{3}}$,

where $\sigma$ is the surface tension of water, $\varepsilon_{\mathrm{o}}$ is the electric constant, and $d$ is the droplet diameter, then the droplet will undergo the Coulomb fission. The Coulomb fission can act as a mechanism of producing the nanoparticles. However, there is no information about the microdroplets in atmospheric air, which carry charges comparable with the Rayleigh limit. On the other hand, the microdroplets may lose the electric charge without disruption as a result of ion evaporation (Iribarne and Thomson, 1976; Gamero-Castano and de la Mora, 2000; McQuinn et al., 2007; Znamenskiy et al., 2003). Thus the role of the Coulomb fission in the evolution of droplets in the real atmosphere is unknown.

The charged nanometer particles in atmospheric air have been detected and studied using the electric mobility spectrometers. The particle size-mobility relation used in data conversion and interpretation includes the particle charge among its parameters. Chapman (1937) drew the conclusion "probably all of the carriers are singly charged" on the basis of Millikan-type experiments and theoretical speculations about the ionic discharging of multiply charged droplets. This conclusion was not reliably proved. The micrometer size droplets generated by splashing may initially be highly multiply charged. The size-mobility relation for particles carrying the Rayleigh-limited maximum charge, the halfmaximum charge and the single elementary charge is shown in Fig. 1. The particles of the mobility of $0.25 \mathrm{~cm}^{2} \mathrm{~V}^{-1} \mathrm{~s}^{-1}$ can be equally interpreted as singly charged particles of the diameter of $2.3 \mathrm{~nm}$, or half-maximum multiply charged droplets of the diameter of $39 \mathrm{~nm}$ or $1 \mu \mathrm{m}$.

The knowledge about the rain-generated nanometer particle bursts is limited. Hõrrak et al. (2006) described the first quantitative measurements made with contemporary instrumentation. The brief analysis of the statistics of the raininduced intermediate ion bursts in Finland was presented by

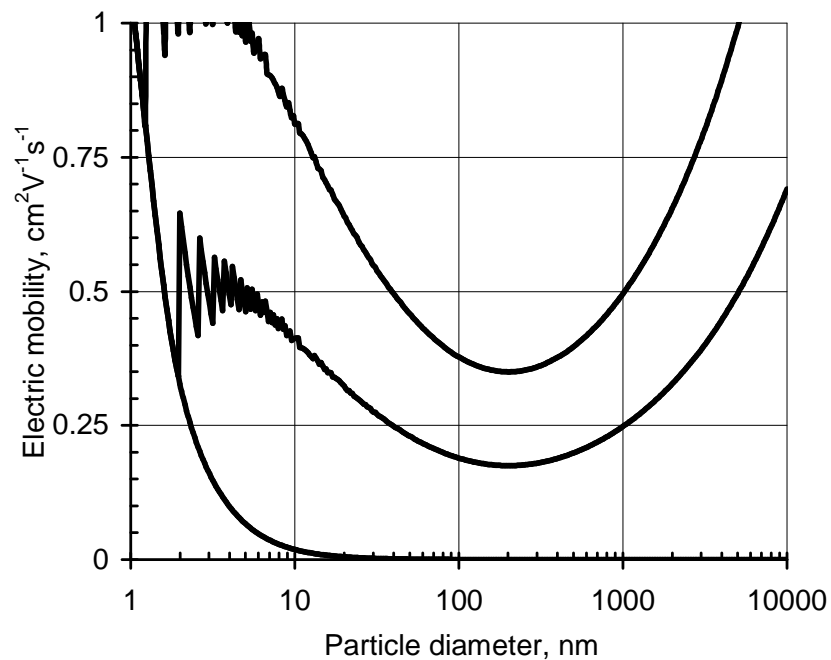

Fig. 1. Electric mobility of charged water particles at the temperature of $10^{\circ} \mathrm{C}$ and the pressure of $1000 \mathrm{mb}$ according to Tammet (1995). Curves from the top to bottom correspond to the particle charge $q_{R}$ (the Rayleigh limit), $q_{R} / 2$, and the single elementary charge.

Hirsikko et al. (2007). In the last paper the rare appearance of the snowfall-induced intermediate ion bursts was first described. However, the physical mechanisms of the intermediate ion generation were not explained and the general question about the possible role of rain-generated nanometer particles in the atmospheric aerosol generation received no definite answer.

\subsection{Objectives of the study}

The general objective of this work is to improve the knowledge about the formation and behavior of charged nanometer aerosol particles (balloelectric ions of mobility of $0.1-$ $0.4 \mathrm{~cm}^{2} \mathrm{~V}^{-1} \mathrm{~s}^{-1}$ ) during rainfall using the electric mobility spectrometry in atmospheric conditions and in the laboratory.

The first basic question was about the nature of ions: which are the balloelectric ions - the multiply charged micrometer particles or singly charged nanometer particles? The reliable answer is a requisite for unambiguous converting of the measured mobility distributions to the size distributions of the particles. Thus the first task of the study was to carry out a specific experiment to evaluate the charges of balloelectric ions.

The second task was to determine, whether the intermediate ions recorded during the rain were of the same nature as the balloelectric ions in the laboratory experiments. The method was the recording of the intermediate ions generated by the splashing of water during the natural rain and generated in a laboratory experiment, and comparing the mobility distributions. The mobility distributions of natural balloelectric ions were identified when analyzing the results 
of long-term measurements of air ion mobility distributions made in Hyytiälä, Finland, and in Tartu, Estonia. These measurements were accompanied with measurements of the meteorological quantities including the rain intensity.

A specific question raised in the present study was: could the rain-time intermediate ion bursts be classified as nucleation bursts or not?

A foresighted objective is to elucidate the physical mechanism of the rain-time intermediate ion bursts. This objective appeared to be pretentious and some specific results of the present study will remain on the level of hypotheses.

The present study is concentrated in the physical problems of negative balloelectric ions. The study of positive balloelectric ions and statistical analysis of rain-induced balloelectric effect will be published later.

\section{Instruments and locations}

The air ion mobility distribution, atmospheric pressure, air temperature and humidity were measured using the Balanced Scanning Mobility Analyzer BSMA (Tammet, 2006). One instrument marked as the BSMA1 was installed permanently at the Hyytiälä SMEAR station (Finland, $61^{\circ} 51^{\prime} \mathrm{N}, 24^{\circ} 17^{\prime} \mathrm{E}$, $181 \mathrm{~m}$ a.s.l., the sampling height of about $2 \mathrm{~m}$ above the ground) operated by the University of Helsinki. The measuring station is surrounded by a boreal Scots pine forest of the height of about $14 \mathrm{~m}$. The surroundings and operation of the station were described by Hari and Kulmala (2005). The second analyzer marked as the BSMA2 was installed near the roof of the Physic Building of the University of Tartu, Estonia $\left(58^{\circ} 23^{\prime} \mathrm{N}, 26^{\circ} 43^{\prime} \mathrm{E}, 72 \mathrm{~m}\right.$ a.s.l., the sampling height of about $1 \mathrm{~m}$ above the flat bitumen-covered roof), and for the short terms removed from this location when the laboratory experiments were performed. The experiments were carried out in a special small laboratory room in the same building.

The BSMA is designed to measure the mobility distributions of cluster ions and charged nanometer particles in the mobility range of $0.032-3.2 \mathrm{~cm}^{2} \mathrm{~V}^{-1} \mathrm{~s}^{-1}$ in the natural atmosphere. The air flow in the BSMA of about $401 \mathrm{~s}^{-1}$ exceeds the air flow in traditional aerosol instruments by 2-3 orders of magnitude. A high flow rate reduces the inlet loss of high diffusive ions and particles, and suppresses the possible transformation of ions inside the instrument. The adsorption of ions of the highest mobility in the entrance tract of the BSMA is about $20 \%$. The adsorption is numerically compensated and the remaining component of uncertainty in calibration is estimated to be about $5 \%$. In the traditional aerosol instruments, the air is heated in the air tracts and different processes can modify the mobility distribution during the passage through the instrument. In the BSMA, the sheath air is taken directly from the atmosphere and deionized in the electric inlet filter. The passage time of the ions as well as the sheath air from the atmosphere to the collector electrode is reduced to $60 \mathrm{~ms}$ and the heating of the air during the pas- sage to the collector does not exceed $0.2 \mathrm{~K}$. There are minor differences in the design of the measuring condensers of the two instruments BSMA1 and BSMA2. The mobility resolution of the BSMA1 proved to be a little better than that of the BSMA2. The instruments were calibrated independently and the difference in instrumental errors can cause a shift up to several percent between the mobilities recorded with the two instruments.

The BSMA consists of two single-channel DMA-type mobility analyzers (one for positive ions and the other for negative ions), which are connected as a balanced bridge circuit equipped with a single electrometric amplifier. A single electrometer system prevents the problems of reliability in the interpretation of peculiarities in the size or mobility distribution, which are possible in the case of multichannel instruments. The full mobility range is scanned while changing the voltages of the repelling electrodes of the analyzers. The inlet is electronically controlled: the electrostatic gates can be closed or opened independently for the positive and negative ions as prescribed in the control program. About 30 scans with different inlet gate regimes (closed or opened) are carried out during a standard 10-min measuring cycle. A cycle results in the records of the mobility distribution $(2 \times 16$ fractions logarithmically uniformly divided on the mobility range of $0.032-3.2 \mathrm{~cm}^{2} \mathrm{~V}^{-1} \mathrm{~s}^{-1}$ ) and the size distribution $(2 \times 10$ size fractions logarithmically uniformly divided in the diameter range of $0.42-7.5 \mathrm{~nm}$ ). The air ion size-mobility relation depends on the temperature and pressure (Tammet, 1995). Built-in environmental sensors of the BSMA (temperature, pressure and humidity) serve the online mobility-size conversion of measurements.

A shortcoming of the BSMA is its relatively high level of random errors in the records of fraction concentrations. The standard deviation during fair weather is $4-8 \mathrm{e} \mathrm{cm}^{-3}$, but it may essentially increase in case of high humidity and especially, during drifting rain and snowfalls. The reason is that small droplets and snow crystals are sucked into the mobility analyzer, where they can generate strong noise pulses. Thus some amount of the rain-time measurements were disqualified because the level of random errors exceeded the signal level.

Some series of mobility distribution measurements were carried out simultaneously using the Air Ion Spectrometer AIS (Mirme et al., 2007) as well. Both instruments, the BSMA and the AIS, are manufactured by Airel Ltd. (http: //airel.ee). The AIS is a wide-range multichannel mobility spectrometer, which covers the diameter range of 0.46$40 \mathrm{~nm}$. Another advantage of the AIS is a better stability during extreme humidity and snowfalls. This is because the air in the AIS is slightly heated and the sheath air is circulating inside the instrument. On the other hand, using of the AIS measurements in the present study could raise specific questions, which are not easy to answer. The air sample should pass through a $0.6 \mathrm{~m}$ long inlet tube and changing temperature may affect the nanoparticles of water inside 
the instrument. The multichannel principle of measuring assures a good time resolution, but the shape of the size distribution may be distorted by imperceptible malfunctioning of some individual channels. This cannot happen in the BSMA, where all fractions are measured using a single electrometric amplifier. Thus all the analysis in the present paper is based only on the BSMA measurements. The AIS data were used only for comparative technical verification of measurements. Actually, the comparison of the AIS and BSMA data did not show any considerable disagreement in the overlapping mobility range.

The intensity and amount of precipitation at the Hyytiälä SMEAR station was measured by the tipping bucket rain counter ARG-100 (resolution $0.2 \mathrm{~mm}$ ) and by the Vaisala rain detector DRD11A installed on the mast at the height of about $18 \mathrm{~m}$ from the ground. The hourly amounts of rain in Tartu were measured by the Electronic Rain Counter manufactured by Davis Instruments Corp. (resolution $0.2 \mathrm{~mm}$ ). The routine measurements of meteorological quantities and air ion mobility and size distributions in the natural environment were stored and processed using the DataDiurna format and software (Tammet, 2007).

\section{Laboratory measurements}

The experiments were carried out according to the classical method of collision of the water jet onto a solid surface. The splashing of rain droplets was imitated using a thin water-jet streaming out from a nozzle of the diameter of $2.5 \mathrm{~mm}$. The water was drawn from the city waterworks and had the TDS (Total Dissolved Solids) of $550 \mathrm{mg}$ per liter as found out by the method of evaporating and weighing of the dry residue. A photo of the jet shows that the water stream broke into droplets, which hit a vertical ceramic wall at the distance of $65 \mathrm{~cm}$ from the nozzle. The flow rate of the water was 55 $\mathrm{cm}^{3} \mathrm{~s}^{-1}$ and the ejection speed about

$11 \mathrm{~m} \mathrm{~s}^{-1}$. The experiment was performed in a small room with the floor size of $2.8 \times 2.1 \mathrm{~m}^{2}$ and the height of $3 \mathrm{~m}$. The flow rate divided to the floor area corresponds to a very heavy shower of $34 \mathrm{~mm} / \mathrm{h}$. The mobility distribution of air ions was measured by the BSMA, which was installed at the distance of about $2 \mathrm{~m}$ from the spot where the water was splashing. The air in the room was slowly circulated, forced by a table fan of the diameter of $38 \mathrm{~cm}$, whose air jet was directed to the splashing site, and additionally by the BSMA itself, whose flow rate was 44 liters per second.

The main objective of the laboratory measurements was to determine the nature of balloelectric ions of the mobility of $0.03-0.5 \mathrm{~cm}^{2} \mathrm{~V}^{-1} \mathrm{~s}^{-1}$ : the singly charged nanometer particles or the multiply charged micrometer particles. The idea of the test embodied the different behavior of two kinds of particles during the neutralization with bipolar cluster ions. The neutralization does not affect the mobility of the singly charged particles and can only decrease their concentration.

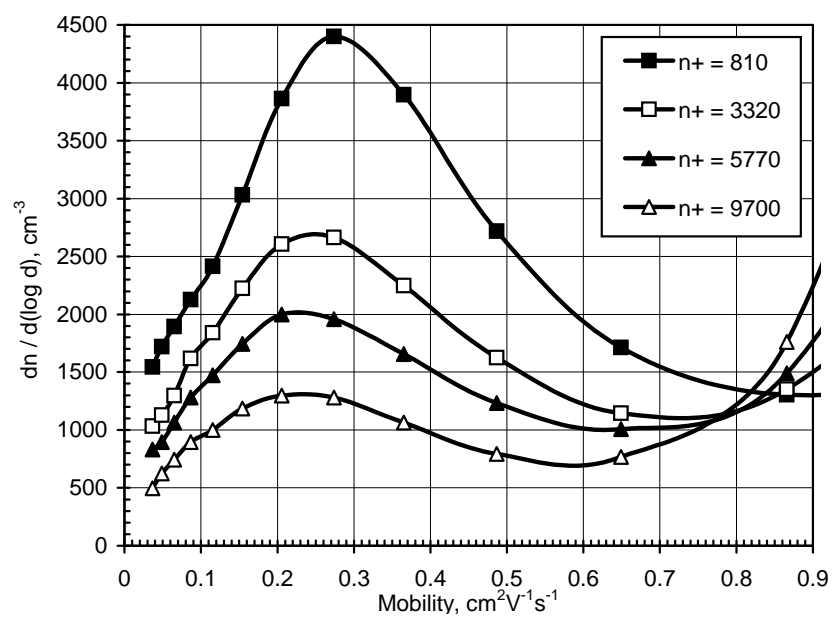

Fig. 2. Effect of particle neutralization on the mobility distribution of the negative balloelectric ions $\left(0.03-0.5 \mathrm{~cm}^{2} \mathrm{~V}^{-1} \mathrm{~s}^{-1}\right)$. The curves correspond to the indicated on the legend concentrations $\left(\mathrm{cm}^{-3}\right)$ of positive cluster ions of the mobility above $0.56 \mathrm{~cm}^{2} \mathrm{~V}^{-1} \mathrm{~s}^{-1}$. The concentration $n+=810 \mathrm{~cm}^{-3}$ is the natural level of ionization in the experiment room.

The behavior of the multiple charged particles is different. Encountering with an oppositely charged cluster ion will decrease the charge of a multiple charged particle, which follows in the proportional decrease in the mobility of the particle.

The cluster ions were generated by beta rays emitted from a weak Sr-90 source. The concentration of cluster ions was controlled by screening the beta rays by aluminum sheets of proper thickness and recorded together with the intermediate ions measured by the BSMA. The BSMA recorded the average mobility distribution for both negative and positive ions for ten-minute cycles. The ten-minute cycles were made alternately in the conditions of four different levels of beta ray ionization. The distributions presented in Fig. 2 are averages over 5 to 9 ten-minute measurement cycles made during one day (12 March 2007). The environmental conditions during the measurements with the activated water jet were: air temperature $11.7-12.1^{\circ} \mathrm{C}$, relative humidity $74-86 \%$, atmospheric pressure $976-982 \mathrm{mb}$. The results are discussed in the next sections of the present paper.

No essential differences were detected when the measurements were repeated in other days. The variations of results between different ten-minute cycles used in calculating the averages for Fig. 2 are illustrated in Fig. 3. It shows a slow drift of ion concentration between repeated cycles, but not a change of the mode in the mobility scale. A source of the drift was the variation of the waterworks pressure. The experiment was carried out in an ordinary, not airtight laboratory room and some additional drift of results during the day may be caused by the natural exchange of the room air. The drift is suppressed in averages by means of the balanced 


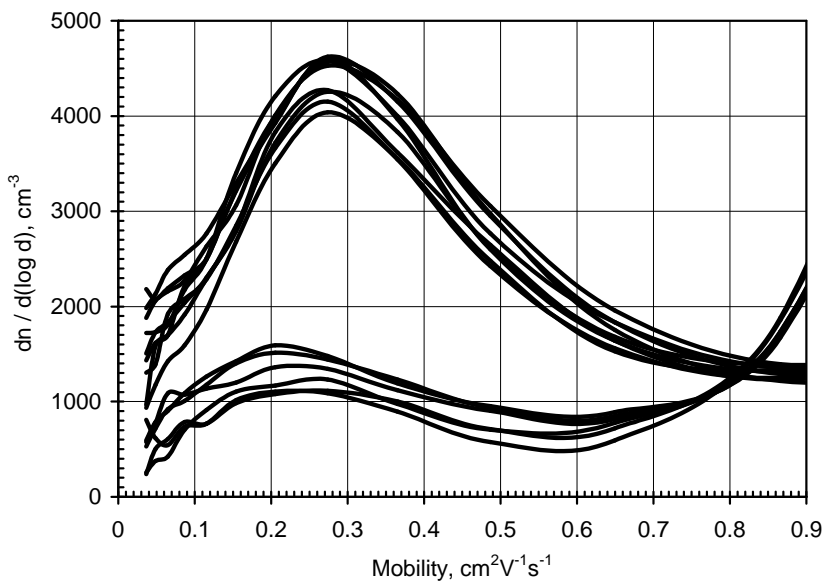

Fig. 3. Individual ten-minute negative ion mobility distributions, used in calculating the averages for Fig. 2. Upper 9 curves are measured at $n+=810 \mathrm{~cm}^{-3}$ and lover 6 curves at $n+=9700 \mathrm{~cm}^{-3}$.

alternating of the ionization level during the measurements. Figure 3 additionally shows remarkable random fluctuations at the mobilities below $0.15 \mathrm{~cm}^{2} \mathrm{~V}^{-1} \mathrm{~s}^{-1}$, which is explained as the instrumental noise of the BSMA. The mobility fractions below $0.1 \mathrm{~cm}^{2} \mathrm{~V}^{-1} \mathrm{~s}^{-1}$ were not used when calculating the concentrations of characteristic balloelectric ions. The drift and noise of ion concentrations above $0.1 \mathrm{~cm}^{2} \mathrm{~V}^{-1} \mathrm{~s}^{-1}$ are low and do not affect the discussion in the present study.

The diagrams in Fig. 2 allow concluding that the representative range of balloelectric intermediate ions can be discriminated within five BSMA mobility fractions covering the range of $0.1-0.42 \mathrm{~cm}^{2} \mathrm{~V}^{-1} \mathrm{~s}^{-1}$. The concentrations of representative intermediate ions in this range are denoted below $N+$ and $N-$ The positive cluster ions are discriminated within the mobility range of $0.56-3.2 \mathrm{~cm}^{2} \mathrm{~V}^{-1} \mathrm{~s}^{-1}$ and their concentration is denoted $n+$. The negative cluster ions are discriminated within the mobility range of 0.75 $3.2 \mathrm{~cm}^{2} \mathrm{~V}^{-1} \mathrm{~s}^{-1}$ and their concentration is denoted $n-$. The summary of the integrated results of all laboratory measurements on 12 March 2007 is presented in Table 1.

The last two rows of Table 1 present the results of an extra experiment carried out to check the effect of the external electric field on the balloelectric effect. The splashing site on the ceramic wall was surrounded by a cylindrical electrode, which allows imitating the atmospheric electric field. These measurements were made in the conditions of natural ionization level and proved that the effect of the external field in the limits of the typical atmospheric electric field is negligible in the performed experiments.

\section{Field measurements of rain-generated nanometer ions}

The initial dataset contained all measurements of natural atmospheric ions carried out by means of the BSMA at the
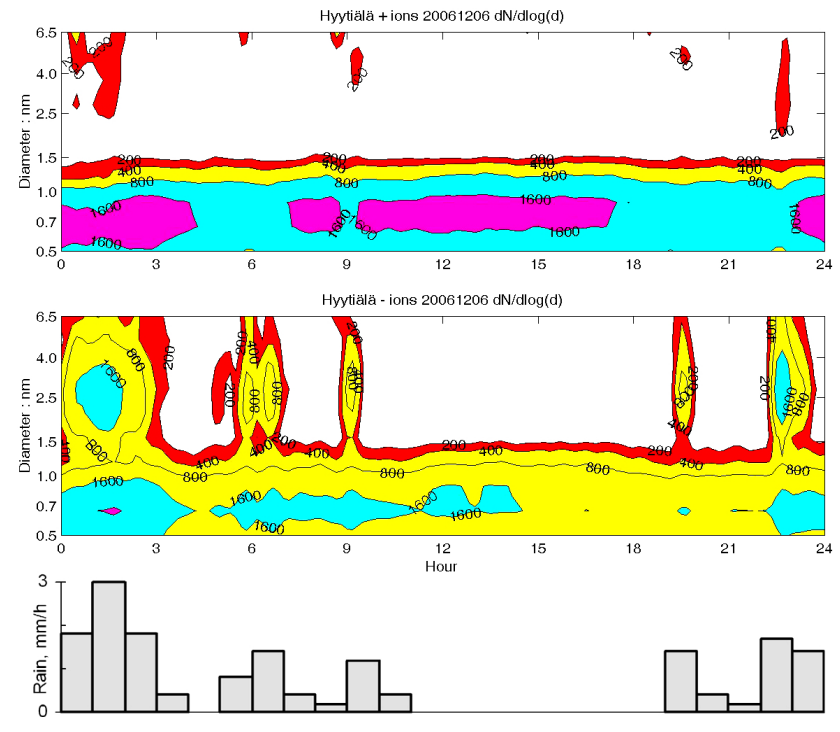

Fig. 4. Intermediate ion size distributions and rain intensity in Hyytiälä, 6 December 2006. Air temperature varied between 5.0 and $8.5^{\circ} \mathrm{C}$ and relative humidity varied between 83 and $96 \%$ during the day.

Hyytiälä SMEAR station from 20 March 2003 until 27 December 2006 and in Tartu from 2 April 2004 until 27 December 2006. The air ion mobility and size distributions are presented in the dataset with the time step of $10 \mathrm{~min}$, the rain intensity in Hyytiälä with the time step of $30 \mathrm{~min}$ and in Tartu with the time step of $60 \mathrm{~min}$. The 10-min time step is used only in the case studies and the statistical analysis is based on the hourly averages. Only such hours are considered when the air ion mobility and size distributions and measurements of air pressure, temperature, humidity, and precipitation intensity were simultaneously available and the temperature of the air did not drop below zero. Fine droplets sucked into the instrument tend to induce enhanced fluctuations of the electrometric signal and about $1.5 \%$ of the hours were rejected because of estimated instrument-produced random errors above $40 \mathrm{~cm}^{-3}$ per mobility fraction. The total number of available measuring hours in Hyytiälä was 15569 and in Tartu 11948. Most of these hours were without rain, the number of rainy hours under consideration was 1183 (7.6\%) in Hyytiälä and 750 (6.3\%) in Tartu. The amount of precipitation below of the rain gauge resolution $(0.2 \mathrm{~mm})$ was not detected and such hours were not included into the analysis of rain events. The maximum of one-hour precipitation in the dataset is $10.8 \mathrm{~mm}$ in Hyytiälä and $10.4 \mathrm{~mm}$ in Tartu. The distribution of the measurements according to the rain intensity is given in Table 2.

An example of diurnal variation of the air ion size distribution is plotted in Fig. 4. A plot represents the map of isolines of the air ion distribution according to the decimal logarithm of the diameter. The scale of electric mobility is converted into the scale of particle mass diameter according to Tammet 
Table 1. Average concentrations of representative intermediate ions $N+$ and $N-$ and cluster ions $n+$ and $n-$ according to the regimes of beta radiation (levels $0 \ldots 3)$, water jet $\left(0=\right.$ off and $1=$ on), and external electric field $E$. Concentrations are expressed in $\mathrm{cm}^{-3}$.

\begin{tabular}{ccrcrrrrc}
\hline Water jet & Beta level & $E$ V/m & Number of cycles & $n+$ & $n-$ & $N+$ & $n-$ & $N+/ N-$ \\
\hline 0 & 0 & 0 & 2 & 822 & 496 & -6 & 2 & - \\
0 & 1 & 0 & 3 & 4475 & 3072 & 3 & 18 & - \\
1 & 0 & 0 & 9 & 812 & 1087 & 308 & 2203 & 0.14 \\
1 & 1 & 0 & 5 & 3322 & 2642 & 197 & 1450 & 0.14 \\
1 & 2 & 0 & 6 & 5765 & 4341 & 138 & 1107 & 0.12 \\
1 & 3 & 0 & 6 & 9697 & 6908 & 105 & 731 & 0.14 \\
1 & 0 & +500 & 3 & 858 & 1045 & 252 & 1974 & 0.13 \\
1 & 0 & -500 & 3 & 817 & 985 & 273 & 1960 & 0.14 \\
\hline
\end{tabular}

Table 2. Number of measurements, average temperature and relative humidity during the rain hours depending on the rain intensity. The hours with negative temperatures are excluded.

\begin{tabular}{crrcrrc}
\hline Rain mm/h & \multicolumn{3}{c}{ Hyytiälä } & \multicolumn{3}{c}{ Tartu } \\
& Hours & $\mathrm{T},{ }^{\circ} \mathrm{C}$ & $\mathrm{RH}, \%$ & Hours & T, ${ }^{\circ} \mathrm{C}$ & $\mathrm{RH}, \%$ \\
\hline $0.1-0.9$ & 863 & 7.5 & 69 & 573 & 8.7 & 88 \\
$1.0-1.9$ & 222 & 7.9 & 73 & 115 & 10.9 & 89 \\
$2.0-2.9$ & 66 & 7.3 & 78 & 30 & 13.2 & 87 \\
$\geq 3.0$ & 32 & 11.1 & 77 & 32 & 14.7 & 85 \\
\hline
\end{tabular}

(1995) assuming that all particles are singly charged. This assumption is based on the results of the laboratory experiments and justified in the discussion below. The example expressively shows the correlation of the negative intermediate ion concentration with the rain intensity. The mode of the particle diameter scale in all bursts is about $2.5 \mathrm{~nm}$. Accompanying generation of positive nanoparticles is weak but clearly visible in the diagram.

The main factor of the generation of intermediate ions during the rain is the rain intensity. Thus the average mobility distributions were calculated for four classes of rain intensity, which are specified in Table 2. The results for measurements in Hyytiälä are shown in Fig. 5 and for measurements in Tartu in Fig. 6. The number of the high-intensity rain hours was not large and the effect of the BSMA instrumental errors may be visible in the subrange of the lowest mobilities. The increasing number of ions in the mobility range of cluster ions above $0.5 \mathrm{~cm}^{2} \mathrm{~V}^{-1} \mathrm{~s}^{-1}$ was also detected and it correlated with the rain intensity. This effect remains an open question for future studies.

\section{Discussion}

Curves in Figs. 2, 5, and 6 show no substantial differences between the shapes of mobility distributions in the mobility range of $0.04-0.5 \mathrm{~cm}^{2} \mathrm{~V}^{-1} \mathrm{~s}^{-1}$ irrespective whether the balloelectric ions were generated in the laboratory or gen-

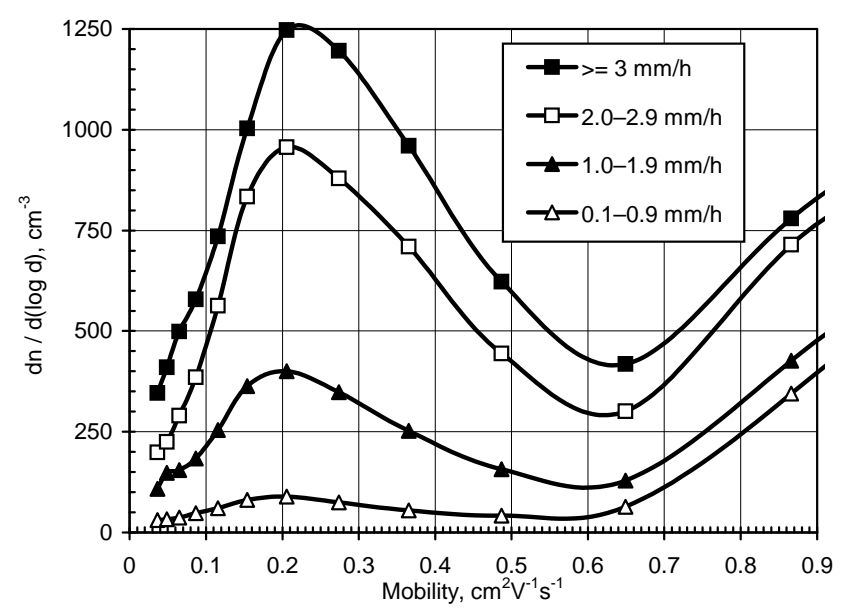

Fig. 5. Average mobility distribution of atmospheric ions during the rain of different intensity in Hyytiälä.

erated by natural rain at two different locations. Most of the balloelectric ions in all measurements had the mobility in the range of $0.1-0.5 \mathrm{~cm}^{2} \mathrm{~V}^{-1} \mathrm{~s}^{-1}$ and the mode of the distribution function $\mathrm{d} n / \mathrm{d}(\log d)$ was between 0.20 and $0.27 \mathrm{~cm}^{2} \mathrm{~V}^{-1} \mathrm{~s}^{-1}$.

A mobility spectrometer records the number concentrations of the elementary charges carried by particles. In case of singly charged particles the recorded concentration equals the number concentration of charged particles, but in case of multiple charges, the recorded concentration is a product of the concentration and the average charge of charged particles of one polarity. Thus the partial neutralization of multiply charged intermediate ions by cluster ions should follow in a proportional decrease in the recorded concentration and the mobility of ions because both of these parameters are proportional to the charge of ions. Figure 2 shows no essential decrease in mobility. Actually, the mobility mode at the natural neutralization level with the cluster ion concentration of $n+=810 \mathrm{~cm}^{3}$ is only a little larger than the mode at the strong neutralization level. The numerical data are presented in Table 3 . 
Table 3. Neutralization of negative balloelectric ions with positive cluster ions.

\begin{tabular}{ccccc}
\hline $\begin{array}{c}\text { Concentration of the positive } \\
\text { cluster ions, } \mathrm{cm}^{3}\end{array}$ & $\begin{array}{c}\text { Concentration of elementary } \\
\text { charges carried by the negative } \\
\text { balloelectric ions in the mobility } \\
\text { range of } 0.1-0.42 \mathrm{~cm}^{2} \mathrm{~V}^{-1} \mathrm{~s}^{-1} \mathrm{~cm}^{3}\end{array}$ & $\begin{array}{c}\text { Mobility mode of the } \\
\text { negative balloelectric } \\
\text { ions, } \mathrm{cm}^{2} \mathrm{~V}^{-1} \mathrm{~s}^{-1}\end{array}$ & $\begin{array}{c}\text { Corresponding diameter } \\
\text { of a singly charged } \\
\text { particle, nm }\end{array}$ & $\begin{array}{c}\text { Corresponding number } \\
\text { of the water molecules } \\
\text { in a particle }\end{array}$ \\
\hline 810 & 2200 & 0.27 & 2.22 & 192 \\
3320 & 1450 & 0.25 & 2.32 & 2.44 \\
9770 & 1100 & 0.23 & 2.44 & 253 \\
\hline
\end{tabular}

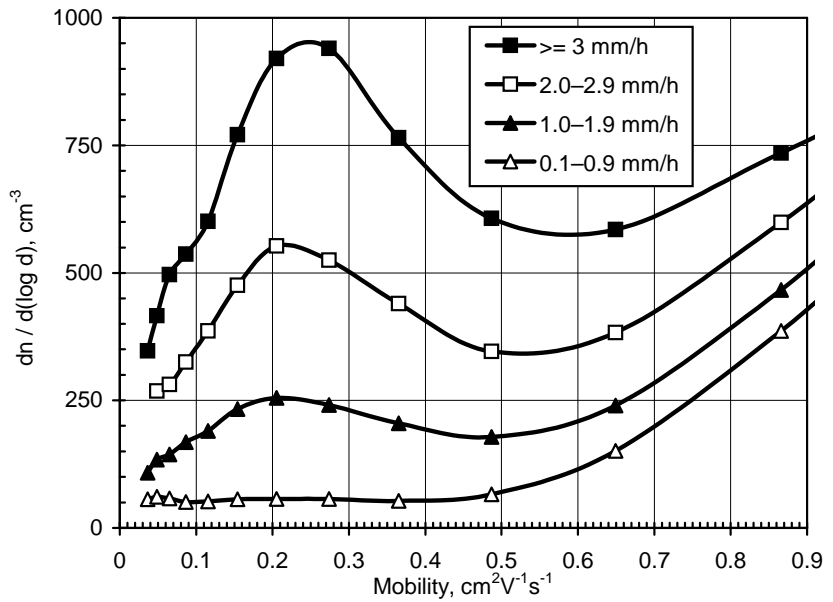

Fig. 6. Average mobility distribution of atmospheric ions during the rain of different intensity in Tartu.

The high neutralization level slightly suppresses the average age of the balloelectric ions detected by the mobility analyzer. Thus the balloelectric ions at the high concentration of cluster ions are less aged when compared with the balloelectric ions at the low concentration of cluster ions. If the balloelectric ions are the slowly evaporating nanoparticles, then the diameter decreases and mobility increases with the age. Another factor of the mobility shift is the dependence of the ion attachment on the size: the balloelectric ions of higher mobility are neutralized a little quicker than the balloelectric ions of low mobility. Both of these effects are in a qualitative accordance with the results presented in Fig. 2 and Table 3.

The results of the neutralization experiment confirm the supposition by Chapman (1937) that the balloelectric ions are singly charged nanometer particles. This conclusion allows considering the concentration of elementary charges recorded by the mobility analyzer as the number concentration of charged nanometer particles, and unambiguously transforming the mobility scale into the particle diameter scale according to the algorithm by Tammet (1995).
The mobility interval $0.1-0.5 \mathrm{~cm}^{2} \mathrm{~V}^{-1} \mathrm{~s}^{-1}$ corresponds to the singly charged particle diameter interval of $1.6-4.0 \mathrm{~nm}$ (air pressure is expected $1000 \mathrm{mb}$ and temperature $10^{\circ} \mathrm{C}$ ). The diameters corresponding to the mobility modes are shown in Table 3.

Another problem discussed on basis of the laboratory experiment is the substance of the balloelectric ions: the water or dry residue. The total dissolved solids (TDS) of the water used in the laboratory experiment $550 \mathrm{mg} / \mathrm{l}$ exceeds the TDS of the rainwater about 50 times or more. There are no reasons to assume a radical dependence of the initial mechanical dispersion of the water on the TDS. If the initial droplets of water are about the same size for the rainwater and waterworks water, then the diameters of dry residues should differ by at least three times. However, the size of the balloelectric ions in the laboratory experiment is about the same as the size of rain-generated balloelectric ions, compare the Figs. 2, 5 and 6 . Thus the hypothesis of dry balloelectric ions is to be rejected.

The existence of a measurable amount of water nanoparticles in the air seems to be paradoxical in the traditional viewpoint of aerosol science. The Knudsen number of nanoparticles is high and their evaporation can be described by means of kinetic theory. The necessary equations are available in textbooks, e.g. Green and Lane (1964). The flux of evaporating mass from the unit of the surface of a neutral droplet is

$j=\alpha \sqrt{\frac{k T}{2 \pi m}}\left(S_{K}-\mathrm{RH}\right) \rho_{S}$,

where $\alpha \approx 1$ is the accommodation coefficient of water molecules (Kulmala and Wagner, 2001; Winkler et al., 2004), $k$ is the Boltzmann constant, $T$ is the absolute temperature, $m$ is the mass of the water molecule, $S_{K}$ is the Kelvin coefficient, RH is the relative humidity of the surrounding air, and $\rho_{S}$ is the density of the saturated vapor over a plain surface. The term $\left(S_{K}-\mathrm{RH}\right) \rho_{S}$ expresses the excess density of the saturated vapor over the particle surface. The Kelvin coefficient is

$S_{K}=\exp \left(\frac{4 \sigma m}{\rho_{w} k T d}\right)$, 
where $d$ is the diameter of the droplet, $\sigma$ is the surface tension and $\rho_{w}$ is the density of the water. The shrinking velocity of the droplet diameter is $W=2 j / \rho_{w}$ and the corresponding characteristic evaporation time $t_{e}=d / W$ is

$t_{e}=\frac{\rho_{w} d}{\alpha \rho_{S}} \sqrt{\frac{\pi m}{2 k T}}\left(\exp \left(\frac{4 \sigma m}{\rho_{w} k T d}\right)-\mathrm{RH}\right)^{-1}$.

The characteristic evaporation time of $2.5 \mathrm{~nm}$ neutral droplets at $10^{\circ} \mathrm{C}$ and $100 \%$ relative humidity does not exceed $1 \mu \mathrm{s}$ according to the equation above. The molecular dynamics simulations by Caleman and Spoel (2007) confirmed that the neglected above effect of electric charge on the evaporation time does not exceed some tens of per cent. $1 \mu \mathrm{s}$ is about 7 magnitudes less than the estimated time of passage of the air to the instrument and 5 magnitudes less than the time of passage of the air through the analyzer. If the balloelectric ions were composed of liquid water at the environmental temperature then the observation of $2.5 \mathrm{~nm}$ particles in the above described measurements would be recognized as impossible.

Caleman and Spoel $(2006,2007)$ proved that the nanometer droplets will quickly cool down to the temperature of $-70^{\circ} \mathrm{C}$ to $-80^{\circ} \mathrm{C}$ when evaporating without heat transfer into vacuum. The Knudsen number for balloelectric ions in the air is in the range of 20-30 where the heat transfer is suppressed but not fully cancelled, and the cooling is expected to be less than during evaporation into vacuum. The cooling droplets will freeze and the evaporation time will increase. The surface properties of $2.5 \mathrm{~nm}$ ice particles are different of the surface properties of the liquid water. A rough estimate of the evaporation speed can be found when neglecting the surface properties and omitting the last term in Eq. (4). The density of the saturated water vapour over plain ice at $-70^{\circ} \mathrm{C}$ is about $3 \times 10^{6} \mathrm{~kg} \mathrm{~m}^{3}$, which results in a rough estimate of the evaporation time of the $2.5 \mathrm{~nm}$ ice particles into vacuum to be about $3.5 \mathrm{~ms}$. This is still about 3 magnitudes less than the time of the air passage to the analyzer. It seems plausible that the actual life time of the $2.5 \mathrm{~nm}$ particles essentially exceeds the above estimate. A possible reason may be a specific molecular structure, which suppresses the accommodation coefficient or the vapour pressure near the diameter of $2.5 \mathrm{~nm}$ and induces a maximum in the size distribution.

The water structure has been discussed in the context of balloelectric effect since the fundamental work by Lenard (1915). A pioneering study about water clathrates as atmospheric aerosol particles by Siksna (1973) remained little known. Today, the magic water clusters containing up to 21 molecules are well known in mass-spectrometry (Beyer, 2007). Larger clusters were seldom studied and no magic numbers were found in mass spectrum from 29 to 60 (Yang and Castleman, 1989). Chaplin (1999) proposed that water contains the magic icosahedron aggregates built of 280 water molecules (see details in http://www.lsbu.ac.uk/water/ index 2.html). The diameter of such an aggregate is about
$2.5 \mathrm{~nm}$ and its mobility is about $0.22 \mathrm{~cm}^{2} \mathrm{~V}^{-1} \mathrm{~s}^{-1}$. Tammet (1995) classified the airborne particles according to their kinetic properties into the clusters of the diameter of less than $1.6 \mathrm{~nm}$ and the macroscopic particles of the diameter of above $1.6 \mathrm{~nm}$. An aggregate of 280 water molecules is recognized as a macroscopic particle in the classification by Tammet. However, the internal structure of a Chaplin's icosahedron is typical for clusters and these particles are called the superclusters in the present study. The size of a Chaplin's supercluster is close to the diameter mode of the balloelectric ions.

Tuomi (2006) pointed out the significance of Chaplin's ideas in air ion research and explained that the physical state of the water clusters should not be considered as liquid but rather ice. Laakso et al. (2006) cited Chaplin (1999) when describing the results of a case study of the air ion mobility distribution near a natural waterfall in a preliminary publication. A weak maximum about $2 \mathrm{~nm}$ on the background of considerable fluctuations was detected in this study. However, the reference to Chaplin was left out of the final publication of this research (Laakso et al., 2007).

Chaplin (1999) found a support for the hypothesis of superclusters analyzing X-ray data for the liquid water. The methods of creating the clusters in the mass-spectrometry do not include a mechanism retarding the growth or evaporation near the magic size and are not promising for the study of the isolated Chaplin's superclusters in the gases.

In general, an event of nanometer particle formation in atmospheric air can be called the nucleation burst if the particles are growing and have a potential to reach the size of condensation nuclei. If the rain-induced intermediate ions are the evaporating droplets, then the process is opposite and the event of particle formation cannot be called the nucleation burst. This conclusion is supported by the fact that the typical for nucleation bursts banana-shape diagrams of the evolution of the particle size distribution were not observed during the rain-time intermediate ion bursts (Hirsikko et al., 2007).

\section{Conclusions}

The gradual neutralization of splashing-generated negative intermediate ions by positive cluster ions produced by beta rays of different intensity suppresses the charge concentration of balloelectric ions, but does not cause any essential shift in their mobility distribution. This observation proves that the balloelectric ions of the mobility of $0.1-$ $0.5 \mathrm{~cm}^{2} \mathrm{~V}^{-1} \mathrm{~s}^{-1}$ are mostly the singly charged nanometer particles.

The hypothesis that the balloelectric ions are the dry residues of bigger evaporating droplets contradicts the fact that the balloelectric ions generated from the rainwater have the same size as the charged nanometer particles generated from the waterworks water. The dry residues of the 
waterworks water droplets should have at least three times larger diameter than that of the dry residues of the rainwater droplets of the same initial size. Thus the balloelectric ions can rather be considered as singly charged water nanoparticles.

Splashing of water during the rain and in rain-simulating laboratory experiment generated the balloelectric intermediate ions of similar mobility distribution. The mobilities of most of the balloelectric ions were between 0.1 and $0.5 \mathrm{~cm}^{2} \mathrm{~V}^{-1} \mathrm{~s}^{-1}$ and the mode of the ion size distribution function $\mathrm{d} n / \mathrm{d}(\log d)$ was between 0.20 and $0.27 \mathrm{~cm}^{2} \mathrm{~V}^{-1} \mathrm{~s}^{-1}$. Corresponding diameter range was $1.6-$ $4.0 \mathrm{~nm}$ and the diameter mode range in the $\mathrm{d} n / \mathrm{d}(\log d)$ diagram was $2.22-2.64 \mathrm{~nm}$.

The balloelectric intermediate ions are not composed of the liquid water. When the freezing of droplets and the peculiarities of the particle structure are ignored, then the kinetic theory would predict the characteristic time of evaporation of a $2.5 \mathrm{~nm}$ droplet below $1 \mu \mathrm{s}$. This estimate is inconsistent with the high concentration of balloelectric intermediate ions in the rain and in the laboratory experiment. The high concentration of balloelectric intermediate ions can be explained by evaporative cooling and peculiarities of the molecular structure of nanoparticles. A water particle of the mobility of $0.22 \mathrm{~cm}^{2} \mathrm{~V}^{-1} \mathrm{~s}^{-1}$ and the diameter of $2.5 \mathrm{~nm}$ contains about 280 molecules, which equals the number of molecules in a Chaplin's icosahedron supercluster.

The charged superclusters can be detected by means of the mobility spectrometry of drying nanoparticles but the mechanism of producing these particles at the splashing of water remains still unknown.

The rain-time intermediate ion bursts cannot be considered as the nucleation bursts.

Acknowledgements. This work was supported by the Estonian Science Foundation under grants no 6223 and 7778, the Estonian Research Council Project SF0180043s08 and by the Nordic Center of Excellence BACCI research unit.

Edited by: V.-M. Kerminen

\section{References}

Beyer, M. K.: Hydrated metal ions in the gas phase, Mass Spectrom. Rev., 26, 517-541, 2007.

Blanchard, D. C.: Electrified droplets from the bursting of bubbles at an air-sea water interface, Nature, 175, 334-336, 1955.

Blanchard, D. C.: Positive space charge from the sea, J. Atmos. Sci., 23, 507-515, 1966.

Bühl, A.: Wasserfalleffekt und Oberflächenstruktur von Flüssigkeiten, Kolloid Z., 59, 346-353, 1932.

Burkhardt, E.: Die Erzeugung hoher Spannungen mit Hilfe eines monopolar beladenen Luftstromes, Ann. Phys., 415, 339-370, 1935.
Caleman, C. and Spoel, D.: Temperature and structural changes of water clusters in vacuum due to evaporation, J. Chem. Phys., 125, 154508, doi:10.1063/1.2357591, 2006.

Caleman, C. and Spoel, D.: Evaporation from water clusters containing singly charged ions, Phys. Chem. Chem. Phys., 9, 51055111, doi:10.1039/b706243e, 2007.

Chaplin, M. F.: A proposal for the structuring of water, Biophys. Chem., 83, 211-221, 1999.

Chapman, S.: Carrier mobility spectra of spray electrified liquids, Phys. Rev., 52, 184-190, 1937.

Chapman, S.: Carrier mobility spectra of liquids electrified by bubbling, Phys. Rev., 54, 520-527, 1938a.

Chapman, S.: Interpretation of carrier mobility spectra of liquids electrified by bubbling and spraying, Phys. Rev., 54, 528-533, 1938 b.

Charry, J. M. and Kavet, R. I.: Air ions: physical and biological aspects, CRC Press, Boca Raton, FL, USA, 1987.

Christiansen, C.: Elektrizitätserregung beim Zerspritzen von Flüssigkeiten (Balloelektrizität), Ann. Phys., 345, 107-137 and 233-248, 1913.

Erikson, H. A.: On the nature of the ions in air and in carbon dioxide, Phys. Rev., 24, 502-509, 1924.

Fedorchenko, A. I. and Wang, A.-B.: On some common features of drop impact on liquid surfaces, Phys. Fluids, 16, 1349-1365, 2004.

Fong, C. S., Black, N. D., Kiefer, P. A., and Shaw, R. A.: An experiment on the Rayleigh instability of charged liquid drops, Amer. J. Phys., 75, 499-503, 2007.

Forster, P., Ramaswamy, V., Artaxo, P., Berntsen, T., Betts, R., Fahey, D. W., Haywood, J., Lean, J., Lowe, D. C., Myhre, G., Nganga, J., Prinn, R., Raga, G., Schulz, M., and Van Dorland, R.: Changes in Atmospheric Constituents and in Radiative Forcing, in: Climate Change 2007: The Physical Science Basis, Contribution of Working Group I to the Fourth Assessment Report of the Intergovernmental Panel on ClimateChange, edited by: Solomon, S., Qin, D., Manning, M., Chen, Z., Marquis, M., Averyt, K. B., Tignor, M., and Miller, H. L., Cambridge University Press, Cambridge, UK and New York, NY, USA, 129-234, 2007.

Gamero-Castano, M. and Fernandez de la Mora, J.: Direct measurement of ion evaporation kinetics from electrified liquid surfaces, J. Chem. Phys., 113, 815-832, 2000.

Gathman, S. G. and Hoppel, W. A.: Electrification processes over Lake Superior, J. Geophys. Res., 75, 1041-1048, 1970.

Gilbert, H. W. and Shaw, P. E.: Electrical charges arising at a liquidgas interface, P. Phys. Soc. Lond., 37, 195-214, 1925.

Green, H. L. and Lane, W. R.: Particulate clouds: dusts, smokes and mists, E. and F. N. Spon, London, UK, 1964.

Hari, P. and Kulmala, M.: Station for Measuring EcosystemAtmosphere Relations (SMEAR II), Boreal Environ. Res., 10, 315-322, 2005.

Hirsikko, A., Bergman, T., Laakso, L., Dal Maso, M., Riipinen, I., Hõrrak, U., and Kulmala, M.: Identification and classification of the formation of intermediate ions measured in boreal forest, Atmos. Chem. Phys., 7, 201-210, 2007, http://www.atmos-chem-phys.net/7/201/2007/.

Hõrrak, U., Salm, J., and Tammet, H.: Statistical characterization of air ion mobility spectra at Tahkuse Observatory: Classification of air ions, J. Geophys. Res.-Atmos., 105, 9291-9302, 2000.

Hõrrak, U., Tammet, H., Aalto, P. P., Vana, M., Hirsikko, A., 
Laakso, L., and Kulmala, M.: Formation of charged nanometer aerosol particles associated with rainfall: atmospheric measurements and lab experiment, Report Series in Aerosol Science, 80, 180-185, 2006.

Iribarne, J. V. and Thomson, B. A.: On the evaporation of small ions from charged droplets, J. Chem. Phys., 64, 2287-2294, 1976.

Kulmala, M., Laakso, L., Lehtinen, K. E .J., Riipinen, I., Dal Maso, M., Anttila, T., Kerminen, V.-M., Hõrrak, U., Vana, M., and Tammet, H.: Initial steps of aerosol growth, Atmos. Chem. Phys., 4, 2553-2560, 2004,

http://www.atmos-chem-phys.net/4/2553/2004/.

Kulmala, M., Riipinen, I., Sipilä, M., Manninen H. E., Petäjä, T., Junninen, H., Dal Maso, M., Mordas, G., Mirme, A., Vana, M., Hirsikko, A., Laakso, L., Harrison, R. M., Hanson, I., Leung, C., Lehtinen, K. E. J., and Kerminen, V.-M.: Towards direct measurement of atmospheric nucleation, Science, 318, 89-92, 2007.

Kulmala, M. and Wagner, P. E.: Mass accommodation and uptake coefficients - a quantitative comparison, J. Aerosol Sci., 32, 833841, 2001.

Laakso, L., Hirsikko, A., Grönholm T., Kulmala M., Luts A., and Parts T.-E.: Waterfalls as sources of small charged aerosol particles, Atmos. Chem. Phys., 7, 2271-2275, 2007, http://www.atmos-chem-phys.net/7/2271/2007/.

Lenard, P.: Über die Electricität der Wasserfälle, Ann. Phys., 282, 584-636, 1892.

Lenard, P.: Über Wasserfallelektrizität und über die Oberflächenbeschaffenheit der Flüssigkeiten, Ann. Phys., 352, 463-524, 1915.

Levin, Z.: Charge separation by splashing of naturally falling raindrops, J. Atmos. Sci., 28, 543-548, 1971.

McQuinn, K., Hof, F., and McIndoe, J. S.: Direct observation of ion evaporation from a triply charged nanodroplet, Chem. Commun., 4099-4101, 2007.

Mirme, A., Tamm, E., Mordas, G., Vana, M., Uin, J., Mirme, S., Bernotas, T., Laakso, L., Hirsikko, A., and Kulmala, M.: A wide range multi-channel Air Ion Spectrometer, Boreal Environ. Res., 12, 247-264, 2007.

Natanson, G. L.: Symmetric electrization of droplets by mechanical atomization of liquids, Zh. Fiz. Khim., 25, 779-790, 1951 (in Russian).

Reiter, R.: Charges on particles of different size from bubbles of Mediterranean Sea surf and from waterfalls, J. Geophys. Res., 99, 10807-10812, 1994.
Salm, J. J. and Tamm, E. I.: On the rotor-hydro-ionizers, Acta Comm. Univ. Tartu, 140, 62-70, 1963 (in Russian).

Siksna, R.: Water clathrates as aerosol particles in the atmosphere, Uppsala University Research Institute of Electricity, Uppsala, Sweden, UURIE 48-73 and UURIE 53-73, 11 and 30, 1973.

Tammet, H. F.: Electrization by induction by atomization of liquids, Acta Comm. Univ. Tartu, 140, 90-95, 1963 (in Russian).

Tammet, H.: Size and mobility of nanometer particles, clusters and ions, J. Aerosol Sci., 26, 459-475, 1995.

Tammet, H.: Continuous scanning of the mobility and size distribution of charged clusters and nanometer particles in atmospheric air and the Balanced Scanning Mobility Analyzer BSMA, Atmos. Res., 82, 523-535, 2006.

Tammet, H.: A joint dataset of fair-weather atmospheric electricity, in: Proceedings of the 13th International Conference on Atmospheric Electricity, Beijing, China, 13-17 August 2007, 1, 104107, 2007.

Thoroddsen, S. T., Etoh, T. G., and Takehara, K: High-speed imaging of drops and bubbles, Ann. Rev. Fluid Mech., 40, 257-285, 2008.

Tuomi, T.: Cluster ions and ice, $7^{\text {th }}$ Finnish-Estonian Air Ion and Aerosol Workshop, Pühajärve, Estonia, 22 August 2006, 2006.

Villermaux, E.: Fragmentation, Annu. Rev. Fluid Mech., 39, 419_ 446, 2007.

Wehner, A. P: History of air ion research, in: Air ions: physical and biological aspects, edited by: Charry, J. M. and Kavet, R. I., CRC Press, Boca Raton, FL, USA, 181-197, 1987.

Winkler, P. M., Steiner, G., Vrtala, A., Vehkamaki, H., Noppel, M., Lehtinen, K. E. J., Reischl, G. P., Wagner, P. E., and Kulmala, M.: Heterogeneous nucleation experiments bridging the scale from molecular ion clusters to nanoparticles, Science, 319 , 1374-1377, 2008.

Winkler, P. M., Vrtala, A., Wagner, P. E., Kulmala, M., Lehtinen, K. E. J., and Vesala, T.: Mass and thermal accommodation during gas-liquid condensation of water, Phys. Rev. Lett., 93, 075701, doi:10.1103/PhysRevLett.93.075701, 2004.

Yang, X. and Castleman, Jr., A. W.: Large Protonated Water Clusters $\mathrm{H}^{+}\left(\mathrm{H}_{2} \mathrm{O}\right),(1 \leq \mathrm{n}>60)$ : The Production and Reactivity of Clathrate-like Structures under Thermal Conditions, J. Am. Chem. Soc., 111, 6846-6847, 1989.

Znamenskiy, V., Marginean, I., and Vertes, A.: Solvated ion evaporation from charged water nanodroplets, J. Phys. Chem., 107, 7406-7412, 2003. 